Article

\title{
Improving Fluidization Hydrodynamics of Group C Particles by Mixing with Group B Particles
}

\author{
Ebrahim H. Al-Ghurabi, Abdelhamid Ajbar and Mohammad Asif * (D) \\ Department of Chemical Engineering, King Saud University, P.O. Box 800, Riyadh 11421, Saudi Arabia; \\ alghurabi83@windowslive.com (E.H.A.-G.); aajbar@ksu.edu.sa (A.A.) \\ * Correspondence: masif@ksu.edu.sa; Tel.: +966-56-981-7045
}

Received: 8 August 2018; Accepted: 22 August 2018; Published: 27 August 2018

Featured Application: As a first step towards developing a simple yet cost-effective technique based on the fluidized bed technology for the treatment of carbon dioxide present in post-combustion flue gases from power plants, we have rigorously investigated the improvement in the fluidized bed hydrodynamics of fine adsorbent particles by mixing with group $B$ particles. Any improvement in the fluidization of fine particles will ultimately translate into higher capture efficiency of the carbon dioxide by the fluidized bed containing fine adsorbent powders.

\begin{abstract}
We have developed a new particle-mixing strategy for improving the fluidization hydrodynamics of Geldart group C powders by mixing with small proportions of group B particles. Two different group $C$ particles with widely different physical properties, i.e., $1 \mu \mathrm{m}$ calcium hydroxide powder and $27 \mu \mathrm{m}$ porous activated carbon, were selected for investigation in the present work. A carefully sieved sample of inert sand was used as external group B particles for mixing. Fluidization experiments were carried out, and the quality of the fluidization was assessed using the fluidization index. For the monocomponent fluidization of fine calcium hydroxide powder, pressure drop was sometimes as much as $250 \%$ higher than the effective weight of the bed. The proposed strategy of particle mixing substantially improved its fluidization hydrodynamics. On the other hand, the development of channels and cracks during the monocomponent fluidization of the activated carbon led to gas bypassing, resulting in low pressure drop and poor contact of phases. Particle mixing was found to improve fluidization behavior, and the chi-squared test showed that the best results were obtained with $13 \mathrm{wt} \%$ particle mixing.
\end{abstract}

Keywords: group C particles; assisted-fluidization; particle mixing; fluidization index; chi-squared test

\section{Introduction}

For efficient and effective utilization of the solid phase in process industries, the use of small particles is often recommended because of their high surface areas. A large surface area invariably ensures high heat and mass transfer rates and better utilization of catalyst particles where the internal mass transport resistance controls the overall mass transport process. However, gas-solid contacting involving small particles in process industries poses a major challenge irrespective of whether it is implemented in a fixed or a fluidized mode of operation. When a fluid flows through a fixed bed of solid particles in the laminar flow region, the pressure drop inversely varies with the square of the particle diameter. Thus, the high pressure drop associated with small particles would eventually translate into a high energy cost, thus compromising the cost effectiveness of the process. An otherwise preferred mode of gas-solid contacting for small particles is fluidization. However, fine powders consisting of small particles (less than $30 \mu \mathrm{m}$ in size), often cohesive in nature, are difficult to fluidize as they develop channels and cracks through which the fluidizing gas tend to bypass the solid materials 
present in the bed, thus resulting in poor contact and inefficient mixing. Geldart classified such powders as group $C$ [1]. Similarly, powders typically in the range of hundreds of micrometers, classified as group B, exhibit bubbling behavior, in which a substantial fraction of the fluidizing gas tend to escape as bubbles without coming into contact with the resident solid phase of the fluidized bed. By contrast, powders in the intermediate size range, classified as group A, show smooth and particulate fluidization behavior, resulting in intimate contact and efficient mixing of the gas and solid phases.

To improve the fluidization behavior of solids with poor fluidization hydrodynamics, various techniques and strategies have been proposed in the literature [2-10]. The main objective of these techniques, commonly known as assisted fluidization techniques, is to provide additional energy to the fluidized bed to overcome interparticle forces that are responsible for the cohesive nature and other non-homogeneities during fluidization. Of particular interest in this connection is the fluidization of fine cohesive powders due to their intrinsically high surface area to volume ratios. An extensive review on this topic has recently been presented by Raganati et al. [11]. They pointed out the dominance of interparticle forces as being primarily responsible for the non-homogeneities observed during fluidization. Several studies highlighted the effect of the interparticle force on the fluidization hydrodynamics [12-16] and proposed techniques for their measurement [17]. Among the assisted fluidization technique is the pulsation of the inlet flow to the fluidized bed, which has been shown to improve the fluidization hydrodynamics of ultrafine powders [18-21]. Another extensively employed technique is the introduction of acoustic vibrations during fluidization [22-24]. This technique helps to lower the minimum fluidization velocity and eliminate non-homogeneities in a bed of ultrafine powder [22]. Si et al. [24] used this technique for drying lignite by varying the sound pressure level and frequency and reported the fluidization quality. The rate of drying and drying completion time improved at high sound pressure levels. Despite being effective in improving the quality of the fluidization, this technique is energy intensive and requires modification in the fluidization setup for introducing the acoustic vibration in the bed.

Another simple and cost-effective assisted fluidization technique that does not require input of energy is the addition of external particles. A careful selection of external particles even in small proportions can substantially improve the fluidization hydrodynamics $[7,25,26]$. The addition of external particles of Group A to the bed of nanoparticles suppresses hysteresis and substantially reduces the size of agglomerates $[7,26]$. The objective of the present work is to improve the fluidization hydrodynamics of Group C particles by using the assisted fluidization technique of particle mixing. However, instead of group A particles, we used large group B particles in the present study. This strategy can potentially offer several advantages as compared with group A particles. First, it can help in shifting the properties of the resulting mixture in the intermediate range of group A classification. Second, the milling action of the large and heavy group B particles during fluidization can suppress agglomeration that is often noticed with group $C$ particles, thus improving the fluidization hydrodynamics of the mixture. Third, it can lower the amount of external particles required for achieving comparable efficacy of group A particle mixing. We carried out a detailed study by choosing two different kinds of group $C$ particles such that one of the samples comprised $1 \mu \mathrm{m}$ calcium hydroxide, whereas the other was a high-surface-area porous $27 \mu \mathrm{m}$ activated carbon, which lies almost on the boundary of group C. For the addition of the group B particle, we used a carefully sieved sample of sand with $256 \mu \mathrm{m}$ in size. We carried out fluidization studies in the presence and absence of external particles and evaluated the fluidization quality by computing the fluidization index. The data were then processed using the chi-squared test to characterize the fluidization hydrodynamics.

\section{Experimental}

A schematic of the experiment setup is shown in Figure 1. A vertical Perspex column of $70 \mathrm{~mm}$ internal diameter and $1000 \mathrm{~mm}$ length was used as a test section for fluidization experiments. 
A perforated plate distributor was located at the bottom of the test section to support the solids present in the bed and to ensure uniform distribution of the flow over the entire cross-section of the column. It comprised of a $10 \mathrm{~mm}$-thick Perspex plate containing $1.5 \mathrm{~mm}$ holes on a square pitch such that $4 \%$ of the open area of the distributor area is open. It was covered by a nylon mesh to avoid the raining down of solid particles through the distributor's holes. As shown in Figure 1, a $250 \mathrm{~mm}$-long calming section preceded the test section of the column for eliminating entry effects. The top of the column was connected with a flexible housing to release the outlet gases coming out of the test section to the environment outside the lab and to prevent the buildup of nitrogen inside the lab. Openings along the height of the column were provided for the measurement of the pressure drop. The lowest port was located at a distance of $50 \mathrm{~mm}$ from the distributor to avoid distributor non-uniformities affecting the measurements. Other openings were placed along the height of the column at a multiple of $250 \mathrm{~mm}$ from the distributor.

The inlet flow assembly comprised a compressed nitrogen cylinder that was connected to an electronic mass flow controller for monitoring and controlling the flow of the inlet gas to the test section of the column. We used a sensitive, fast-response, differential, bidirectional pressure transducer with a response time of $1 \mathrm{~ms}$ to measure the global differential pressure drop across the fluidized bed of adsorbent. Its range was \pm 5 inches of water (Omega model 163PC01D36-124, Norwalk, CT, USA). The pressure transducers were carefully calibrated from volts to Pa using a pressure calibrator (Fluke model 718, Calgary, Canada). The voltage signals from the pressure transducer were captured by data acquisition system (DAQ) running LabVIEW software and then transferred to a computer for further processing. As shown in Figure 1, the lower pressure port was located at a distance of $50 \mathrm{~mm}$ from the distributor, whereas the upper port was at a height of $500 \mathrm{~mm}$, thereby providing crucial information about the overall bed dynamics. The lower pressure port was deliberately located away from the bottom of the bed to avoid distributor-level disturbances influencing the pressure data recorded by the transducer $[27,28]$. On the other hand, the location of the upper pressure port was always substantially higher than the total height of the bed even when the bed was fully fluidized. The pressure tap, which was flush with the column wall, was covered with a nylon mesh. The mass flow controller was also controlled using the analog output of the DAQ, whereas the voltage signal of the controller was recorded throughout the experiments.

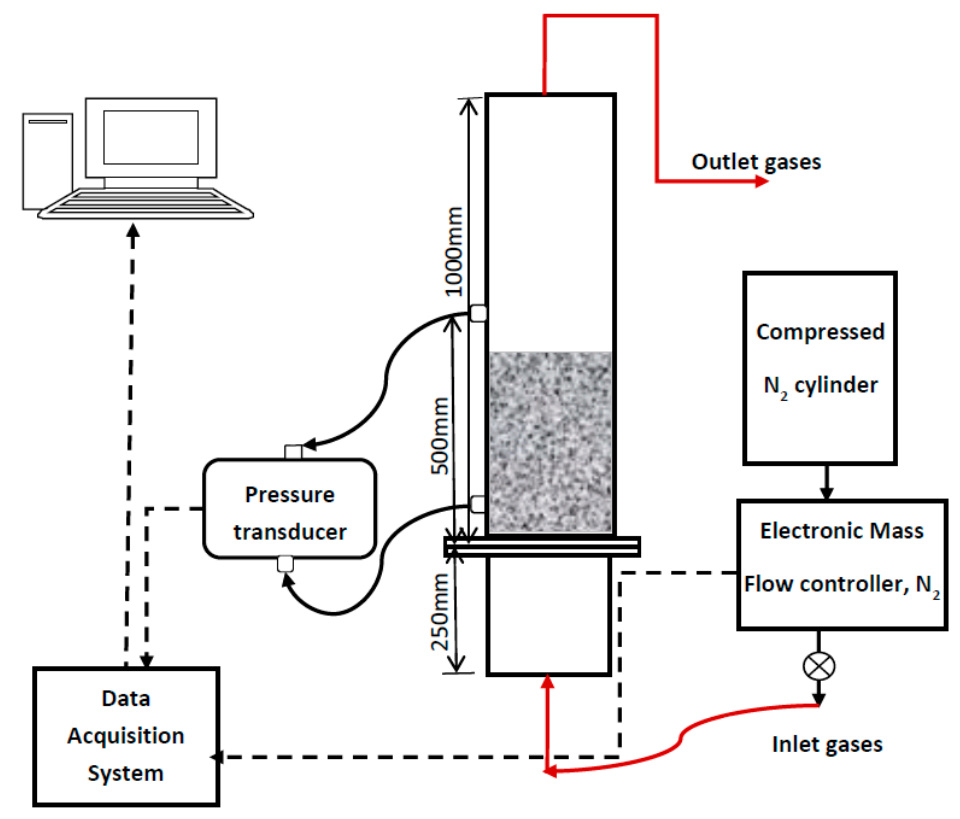

Figure 1. Schematic of the experimental setup used for fluidization at ambient conditions using compressed nitrogen as the fluidizing gas (broken lines represent data communication lines). 


\section{Characterization of Solid Particles}

Two different particle samples belonging to the Geldart group $C$ classification were used in the present work. One was a high-surface-area porous activated carbon (Avonchem, Cheshire, UK), which is commonly used as an adsorbent for a wide variety of environmental applications. As shown in Figure 2, its particle size analysis reveals a wide size distribution, varying in the range of 0.2 to $200 \mu \mathrm{m}$. The volume-mean diameters for three differently-sized analysis runs were $26.14,25.41$, and $27.55 \mu \mathrm{m}$. The SEM image of the activated carbon is shown in Figure 3.

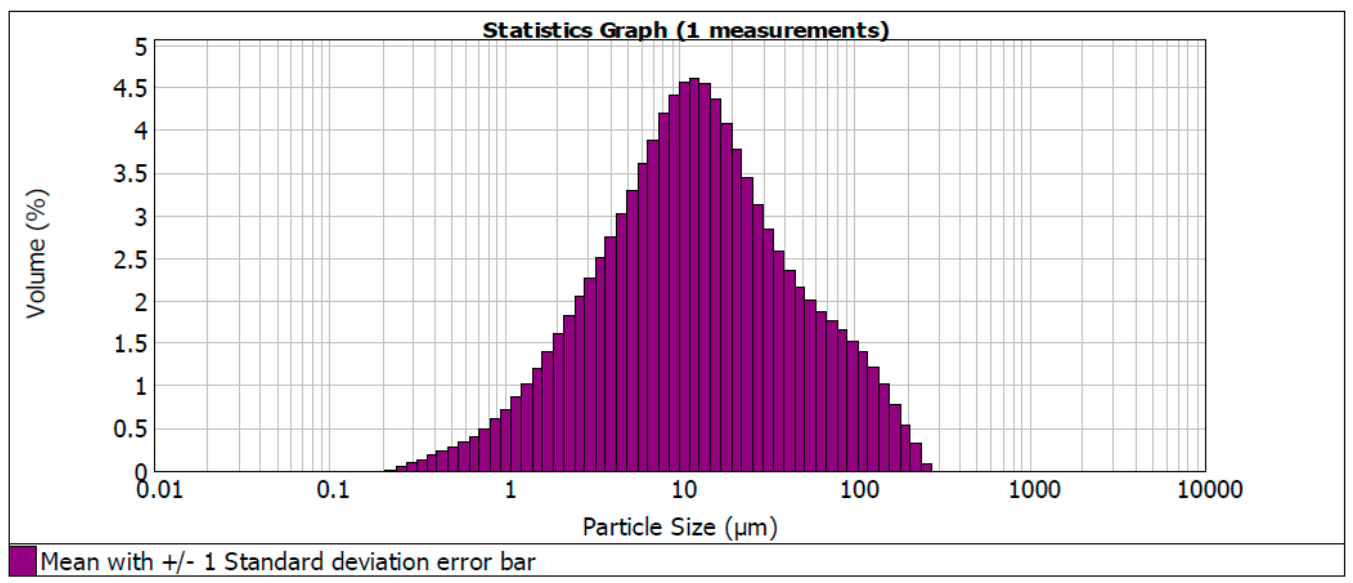

Figure 2. Particle size analysis of the powdered activated carbon sample.

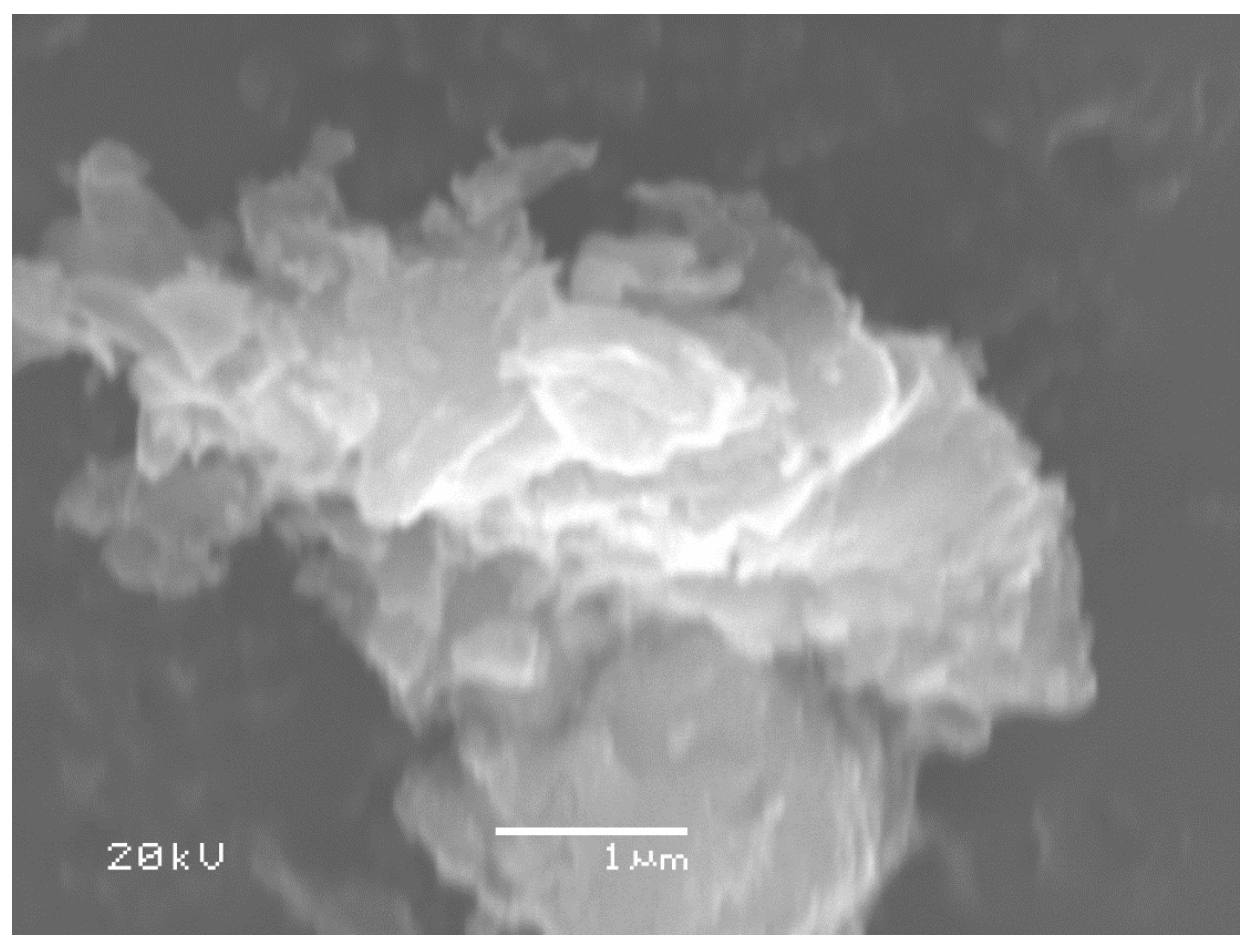

Figure 3. SEM image of activated carbon at a magnification of $20,000 \times$.

Another group $C$ particle sample used was much smaller than calcium hydroxide with a mean particle size of $1.08 \pm 0.23 \mu \mathrm{m}$. Its SEM image, shown in Figure 4, reveals a wide size distribution owing to agglomeration. 
The sample of external inert particles, i.e., sand, was obtained by carefully sieving field sand in the lab and collecting the sample retained between $300 \mu \mathrm{m}$ and $212 \mu \mathrm{m}$ sieves, thus obtaining sample with a mean size of $256 \mu \mathrm{m}$. Its SEM image is shown in Figure 5.

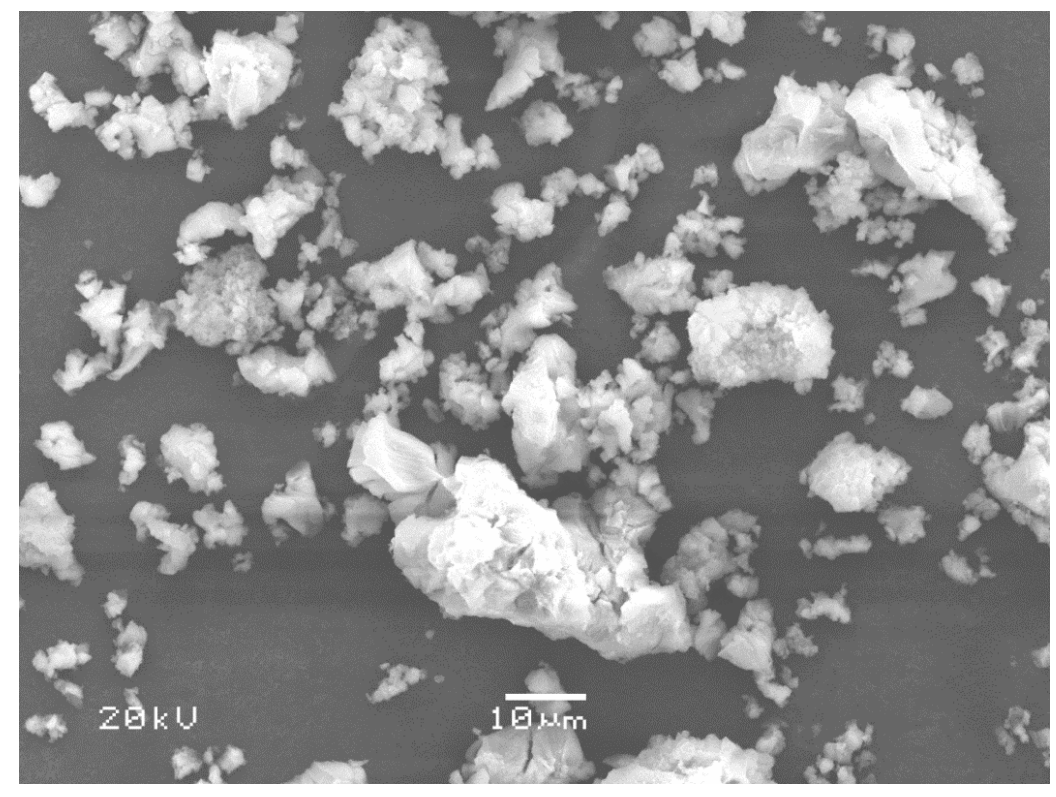

Figure 4. SEM images of calcium hydroxide at a magnification of $1000 \times$.

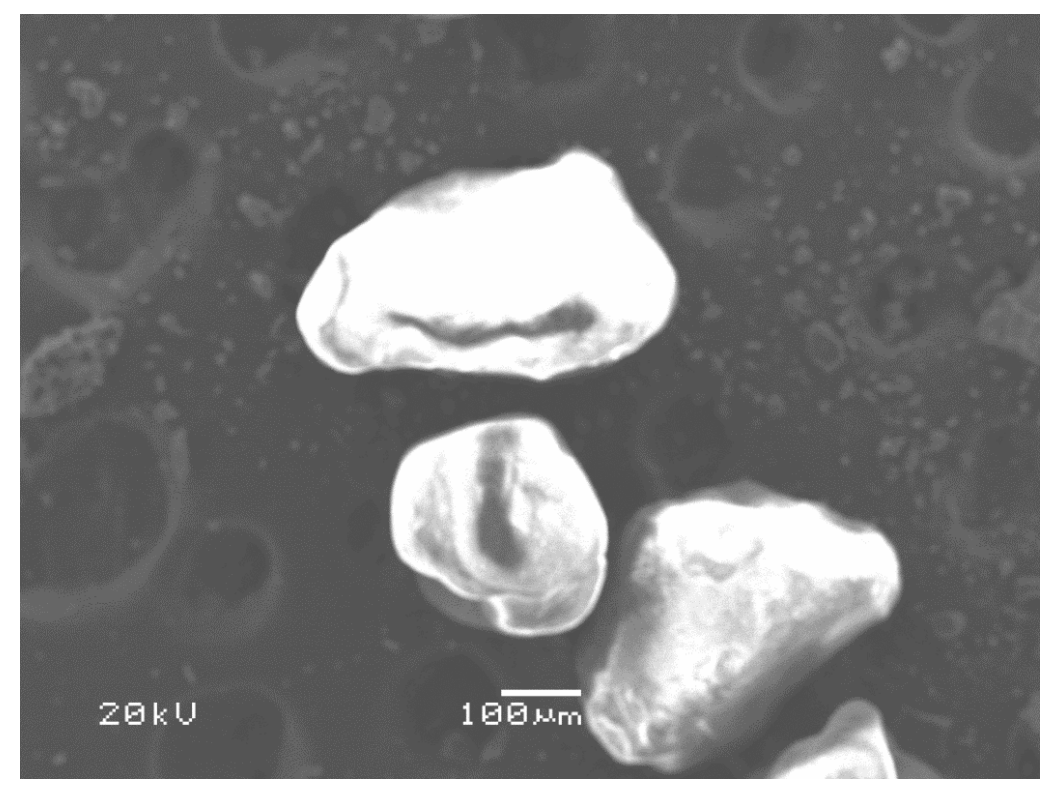

Figure 5. SEM images of inert sand samples used at magnification of $100 \times$.

The physical properties and the theoretical minimum fluidization velocities of all the particle samples are presented in Table 1. To compute the theoretical values of the minimum fluidization velocities, the pressure drop evaluated using the Ergun equation was equated with the fluidized bed pressure drop as follows:

$$
\frac{150 \mu U_{m f}}{d_{p}^{2}} \frac{\left(1-\varepsilon_{m f}\right)}{\varepsilon_{m f}^{3}}+\frac{1.75 \rho_{f} U_{m f}^{2}}{d_{p} \varepsilon_{m f}^{3}}=g\left(\rho_{p}-\rho_{f}\right)
$$


where subscript ' $m f^{\prime}$ ' signifies the incipient fluidization conditions, $d_{p}$ is the particle diameter, $\mu$ is the gas viscosity, $\varepsilon$ the bed void fraction, $U_{m f}$ is the minimum fluidization velocity, $g$ is gravitational acceleration, and $\rho_{P}, \rho_{f}$ are particle and fluid densities, respectively. The Geldart classification of different particle samples used is presented in Table 1 and Figure 6. The resident solid particles of the fluidized bed belong to group $C$, whereas the external inert sand particles belong to group $B$. As mentioned earlier, the selection of group $B$ particles for mixing with group $C$ particles will force the mixture fluidization behavior like group $\mathrm{A}$, which shows a particulate fluidization behavior. The selection of group $C$ particle samples greatly differed from one another as the larger activated carbon lies at the A-C boundary, whereas the smaller calcium hydroxide was as much as 25 times smaller as compared with its larger counterpart.

Table 1. Main characteristics of the particle samples used.

\begin{tabular}{cccccc}
\hline \multirow{2}{*}{ Particle Sample } & Size & Density & Group & \multicolumn{2}{c}{ Theoretical } \\
\cline { 2 - 6 } & $\mathbf{( \mu \mathbf { m } )}$ & $\mathbf{( k g / \mathbf { m } ^ { 3 } )}$ & & $\mathbf{R e}_{\mathbf{m f}}(-/-)$ & $\mathbf{U}_{\mathbf{m f}}(\mathbf{m m} / \mathbf{s})$ \\
\hline Activated carbon & $26.4 \pm 1.1$ & 917 & $\mathrm{C}$ & $3.2 \times 10^{-4}$ & $1.86 \times 10^{-1}$ \\
Calcium hydroxide & $1.08 \pm 0.23$ & 2211 & $\mathrm{C}$ & $5.6 \times 10^{-8}$ & $7.80 \times 10^{-4}$ \\
Inert sand & 256 & 2664 & $\mathrm{~B}$ & $2.9 \times 10^{-1}$ & $1.17 \times 10^{1}$ \\
\hline
\end{tabular}

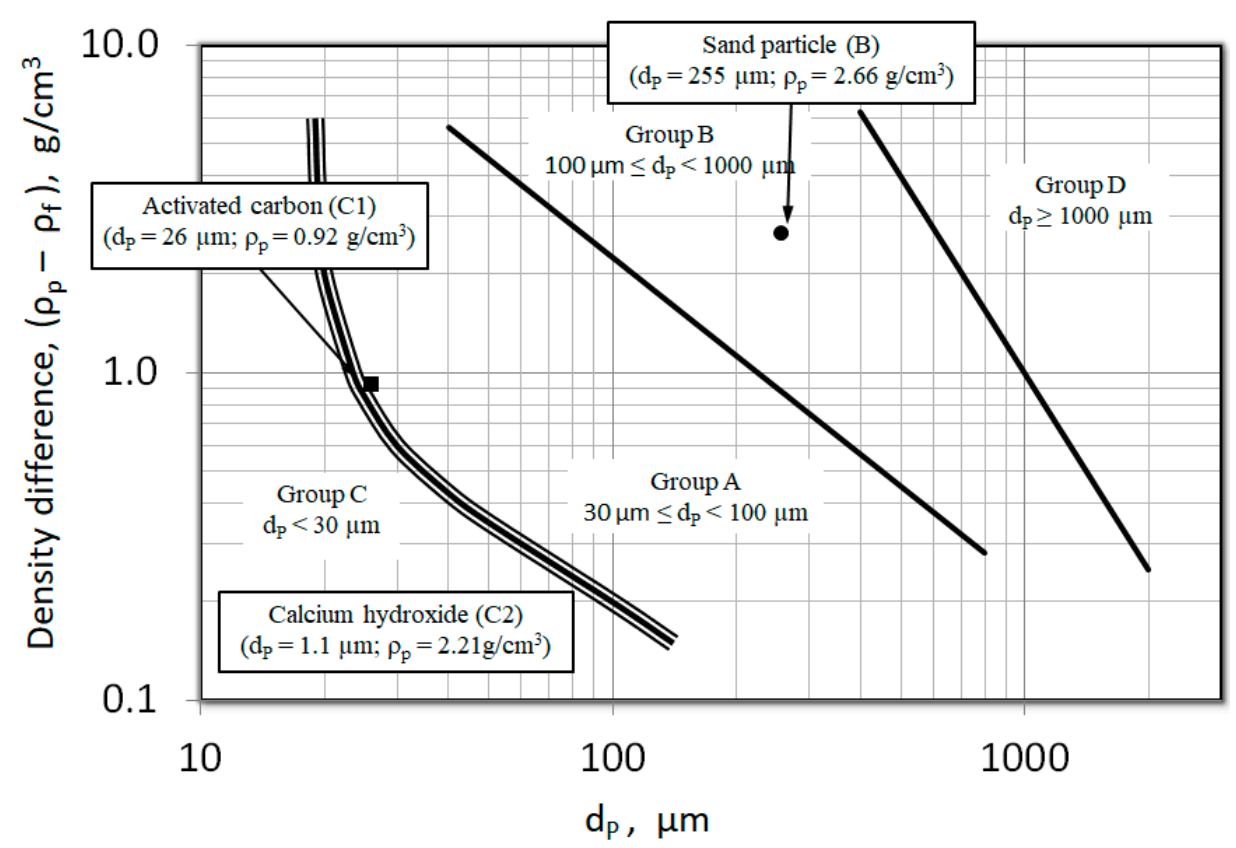

Figure 6. Particle mixing strategy based on the Geldart classification.

The fluidized bed was first loaded with $500 \mathrm{~g}$ group $C$ particles. The initial static bed height was $300 \pm 5 \mathrm{~mm}$ for the case of calcium hydroxide. On the other hand, it was $225 \pm 3 \mathrm{~mm}$ for the bed of activated carbon.

\section{Results and Discussion}

First, we considered the fluidization of the calcium hydroxide by carrying out two runs, as shown in Figure 7. A linear increase in the pressure drop at small velocities was initially observed, owing to the fixed bed mode of contacting between the two phases. However, as the velocity was increased further, a prominent initial depression in the pressure drop profile before an increase sometimes existed. However, above $3 \mathrm{~mm} / \mathrm{s}$, the pressure drop tended to decrease with increased velocity. Moreover, the pressure drop profiles of the two runs had a significant difference, which can be attributed to bed non-homogeneities. Evidently, Run 2 showed better fluidization hydrodynamics as compared 
with Run 1 because the fluidization carried out during Run 1 tended to partially eliminate the bed non-homogeneities. Therefore, Run 2 revealed improved fluidization behavior.

The pressure drop in the initial portion of the pressure drop profile can be correlated with the Ergun equation to compute the effective hydrodynamic diameter of the resident solid particles. The Ergun equation is given as:

$$
\Delta p=\frac{150 \mu U_{o} \Delta L}{d_{p}^{2}} \frac{(1-\varepsilon)^{2}}{\varepsilon^{3}}+\frac{1.75 \rho_{f} U_{o}^{2} \Delta L}{d_{p}} \frac{(1-\varepsilon)}{\varepsilon^{3}}
$$

where $\Delta p$ is the pressure drop across the bed length $\Delta L$, and $U_{o}$ is the superficial velocity of the gas through the bed. For small velocities (laminar regime), the above equation yields a linear relationship between the pressure drop and the velocity. Therefore:

$$
\Delta p=\frac{150 \mu \Delta L}{d_{p}^{2}} \frac{(1-\varepsilon)^{2}}{\varepsilon^{3}} U_{o}
$$

The initial linear part of the pressure-drop profile in Figure 7 was used to compute the effective hydrodynamic diameter by evaluating the mean of both runs and with fitting Equation (3). It is clear from Figure 7 that the following equation:

$$
\Delta p=3670.4 \times 10^{3} U_{0}
$$

yields a linear relationship between the pressure drop and the velocity such that the value of the coefficient of determination $\left(R^{2}\right)$ is 0.9979 . Note that the location of lower port was accounted for in the evaluation of the $\Delta L$ in Equation (3). Substituting the void fraction obtained from the experimental bed height data in Equation (3), and equating the slopes of Equations (3) and (4), it was possible to compute the effective average diameter of the particles present in the bed. Its value was found to be $3.72 \mu \mathrm{m}$. The computed particle size is almost as much as four times higher than the average particle size obtained using the particle size analysis. This result can be attributed to the agglomeration phenomenon due to interparticle surface forces.

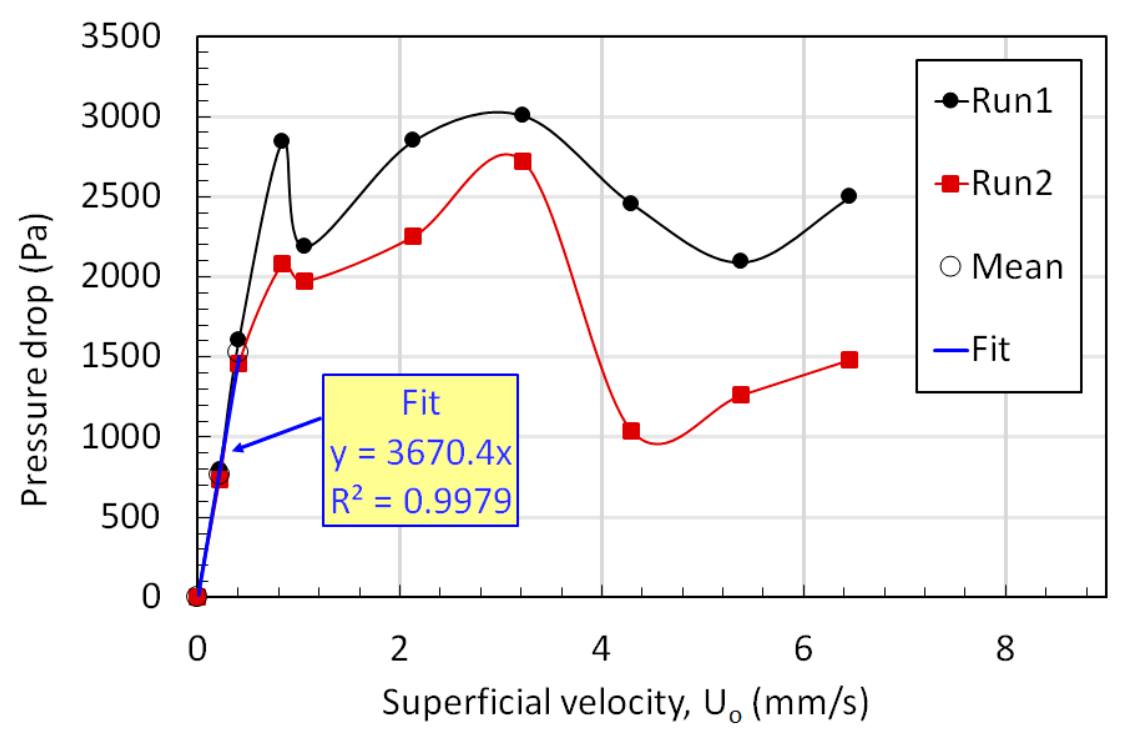

Figure 7. Effect of velocity on the pressure drop profile of the bed of calcium hydroxide during fluidization at ambient conditions using nitrogen gas (the fit is for the initial linear portion of the pressure-drop profile). 
Next, we considered the case of particle mixing by adding $150 \mathrm{~g}$ of group B particles and carrying out the fluidization of the mixed bed. The results are presented in Figure 8. At low velocities, Run 2 and the mixed bed due to partial elimination of bed non-homogeneity during the first fluidization run have not much difference. However, as the bed was fluidized, a substantial difference was observed between the pressure drop profiles. The mixed bed revealed a smooth pressure drop profile. This finding is a clear indication that the addition of external particles helped improve the fluidization behavior of the mixed bed.

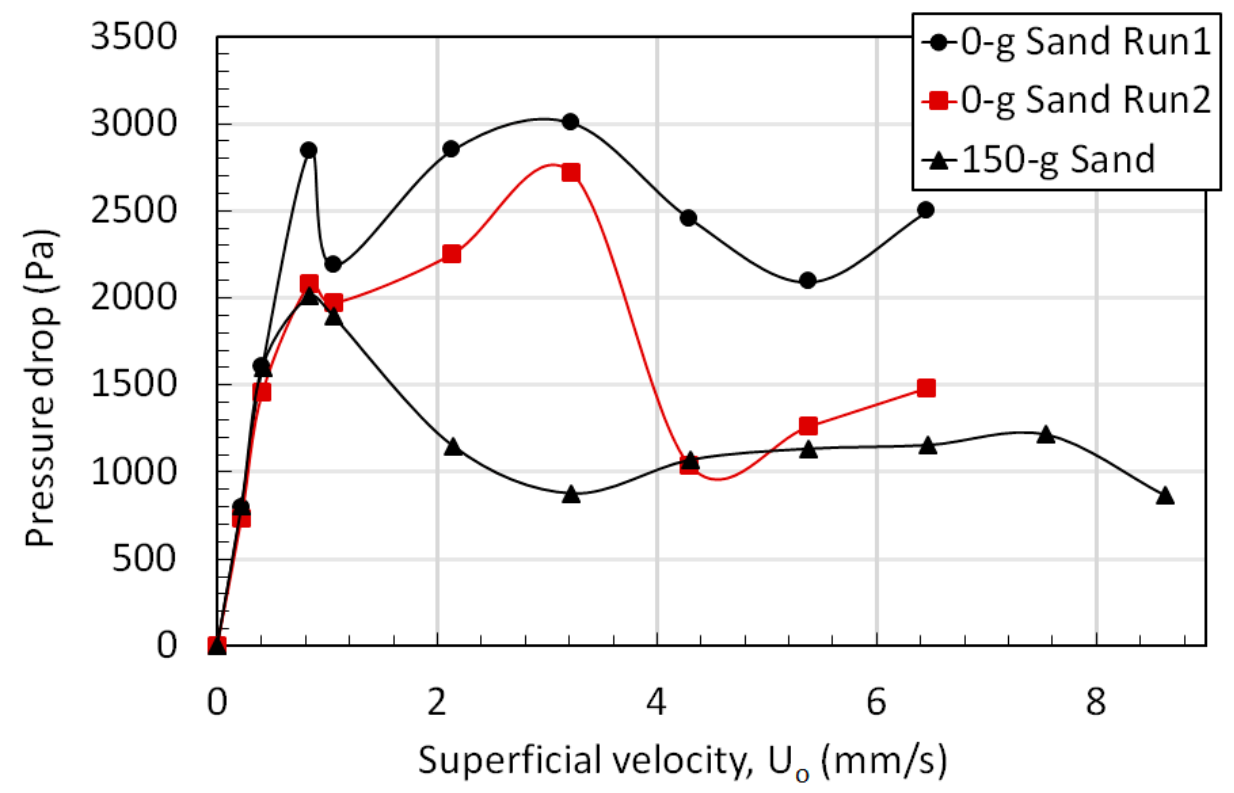

Figure 8. Effect of the velocity and the particle-mixing on the pressure drop profiles of the bed of calcium hydroxide powder using nitrogen gas ambient conditions.

Next, we evaluated the quality of fluidization in terms of a dimensionless parameter, termed as the fluidization index (FI) [29]. For the case of the gas-solid fluidization, this is defined as the ratio of the pressure drop across the bed to the effective bed weight per unit cross-sectional area:

$$
F I=\frac{\Delta p A}{m g}
$$

where $m$ is the amount of solid particles in the bed, $\Delta p$ is the pressure drop across the bed, $A$ is the area of the bed, and $g$ is the gravitational acceleration. Once the incipient fluidization conditions are achieved, the FI should be unity as the pressure drop during fluidization should be equal to the effective weight per unit area of the bed. A low value of FI would indicate the gas channeling and bypassing without sufficiently coming into contact with solid particle present in the bed. This phenomenon is highly undesirable because it will lead to poor mixing. By contrast, a high value of FI would indicate hindrance to the gas flow aside from the usual drag due to the powder cohesiveness. Such kinds of bed non-homogeneities are also undesirable owing to the high energy cost associated with a high pressure drop. Moreover, FI, as a measure of the quality of the fluidization, is applicable only when the bed is fully fluidized.

Figure 9 shows the fluidization indices for the monocomponent bed of calcium hydroxide and the binary-solid bed of calcium hydroxide and sand. We made necessary corrections to account for the location of the lower port in our experimental setup. For the monocomponent bed, FI was sometimes as high as 2.5, which means that the pressure drop was as much as $250 \%$ higher than the effective weight of the bed. By contrast, the mixed bed showed much better fluidization behavior as the FI is near unity once the bed becomes fully fluidized. 


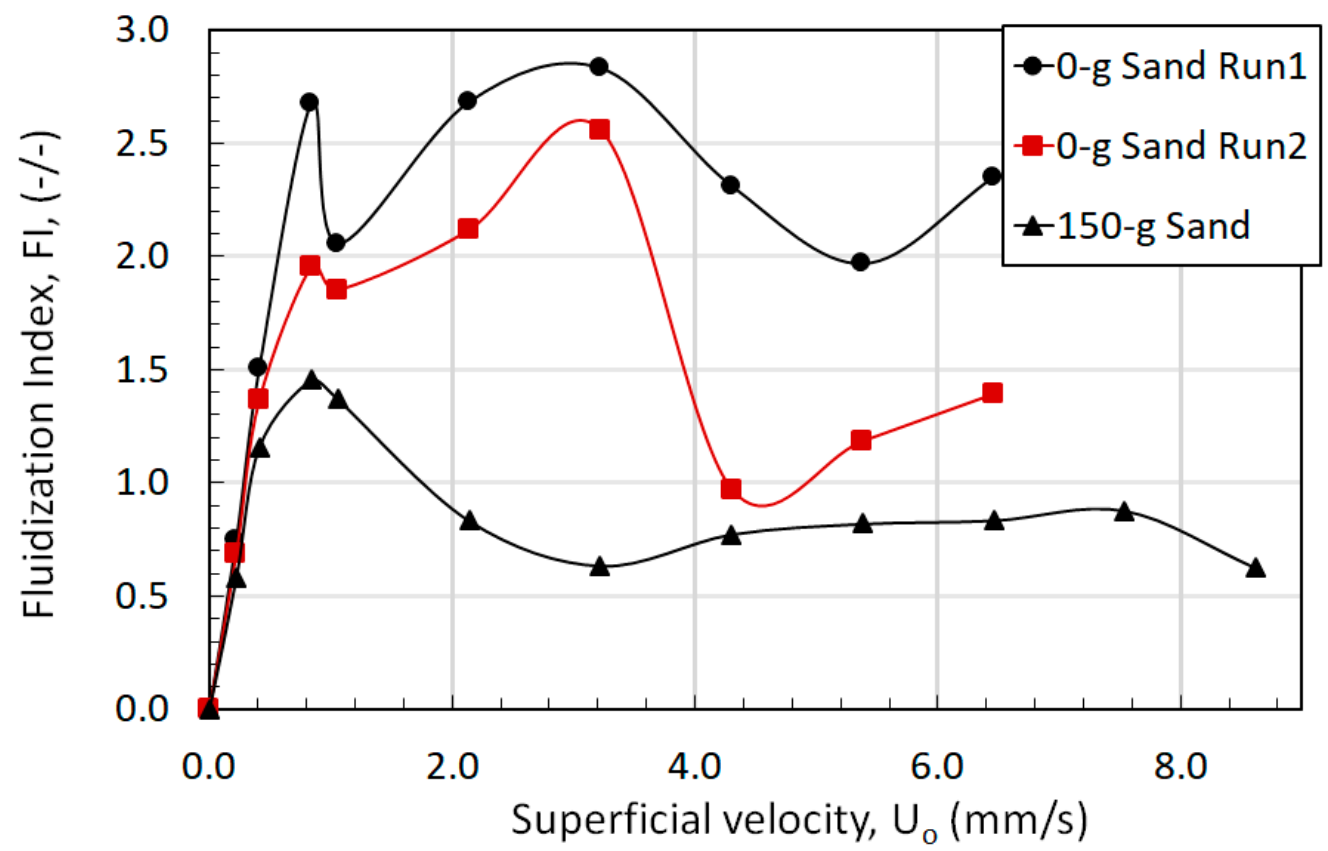

Figure 9. Effect of the addition of external particles on the fluidization hydrodynamics of the monocomponent bed and mixed bed of calcium hydroxide and sand.

To make a precise comparison, we have carried out chi-squared $\left(\chi^{2}\right)$ test, which is a statistical method of assessing the goodness of fit between a set of observed values and those expected theoretically. More precisely, it is essentially the sum of the squares of the differences between the actual data and its expected value with each squared difference divided by the corresponding expected value. The value can be written as:

$$
\chi^{2}=\sum \frac{\left(F I_{\text {actual }}-F I_{\text {expected }}\right)^{2}}{F I_{\text {expected }}}
$$

where the $F I_{\text {expected }}$ is taken as unity because the pressure drop during fluidization should ideally equal the effective weight of the bed. Considering the FI value for each individual velocity when the full fluidization was achieved $\left(U_{0}>2.0 \mathrm{~mm} / \mathrm{s}\right)$, we computed the sum required in Equation (6) for each run. We obtained $\chi^{2}$ values to be $10.65,3.86$, and 0.27 for Run 1 , Run 2 , and the mixed bed case, respectively. A comparison clearly indicates a difference of more than 10 times between the mixed bed and the Run 2 while the same is almost 40 times when the Run 1 is considered. This is a clear indication of the improvement in the hydrodynamics of the fluidization of cohesive calcium hydroxide powder as a result of particle mixing.

We also considered the fluidization of the monocomponent bed of activated carbon, as shown in Figure 10. When the gas velocity was very small, the pressure drop linearly increased with the velocity due to the fixed bed mode of contact of the gas with the resident solid particles. Increasing the velocity further causes particles to move and rearrange, which is reflected in the depression seen in the pressure drop profile. Finally, the pressure drop attains a steady value at high flow rates as the bed of activated carbon becomes fully fluidized. The pressure drop in the initial portion of the pressure drop was correlated with the Ergun equation, which computes the effective hydrodynamic diameter of the resident solid particles. Its value was found to be $27.47 \mu \mathrm{m}$, which is very close to $26.4 \pm 1.1 \mu \mathrm{m}$ obtained from the particle size analysis (Table 1). Although the early onset of fluidization was introduced in the bed at approximately $0.2 \mathrm{~mm} / \mathrm{s}$, the bed appeared to be fully fluidized only when the gas velocity is $1 \mathrm{~mm} / \mathrm{s}$. 


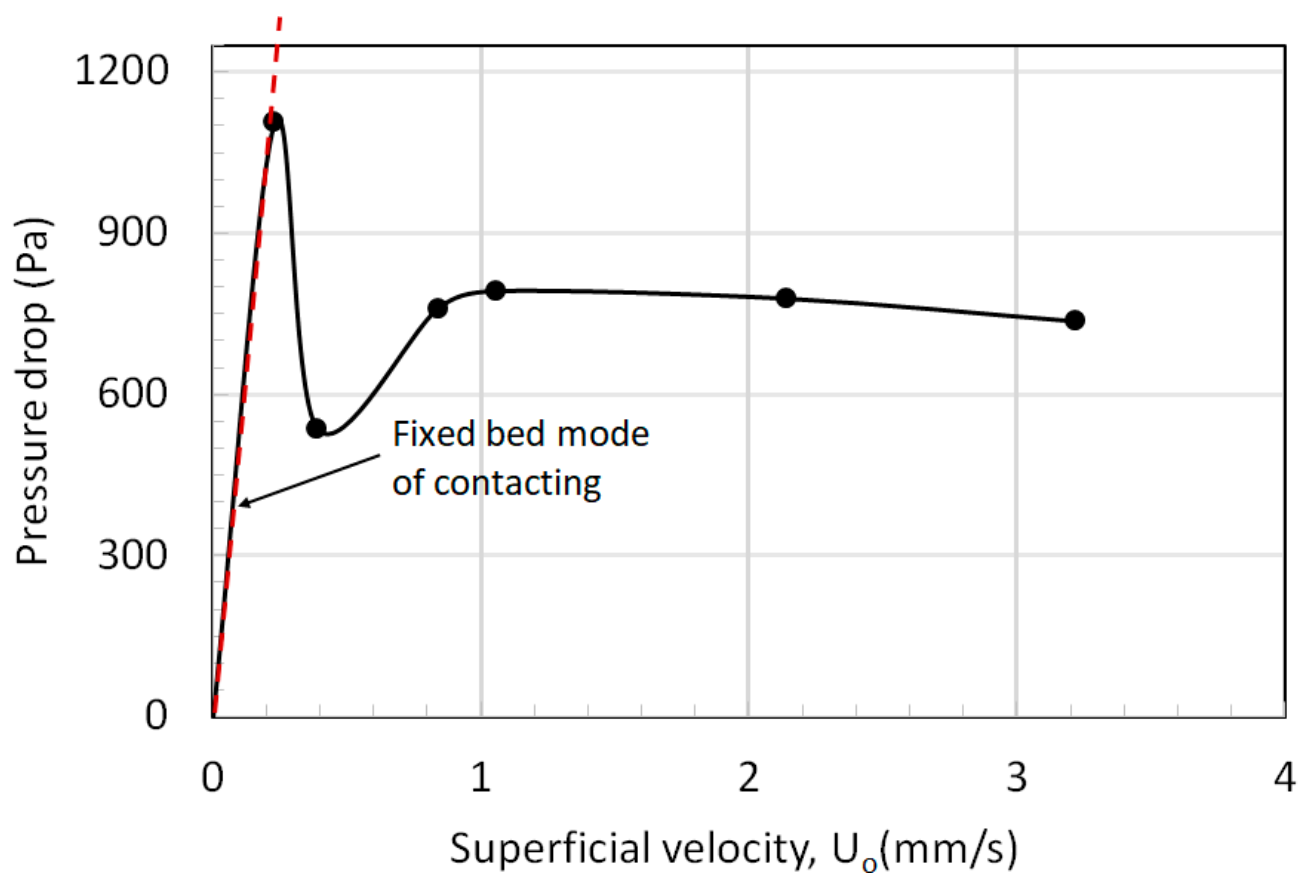

Figure 10. Fluidization behavior of the monocomponent bed of activated carbon at ambient conditions using nitrogen gas.

The effect of the mixing of external group B particles is shown in Figure 11. Here, we broadened the scope of our work by varying the fraction of external particles. Four different cases were considered by gradually increasing the amount of external particles by adding 25, 50, 75, and $150 \mathrm{~g}$ of sand in a bed containing $500 \mathrm{~g}$ of activated carbon. Evidently, the initial slope of the pressure drop profile remained largely unaffected by the particle mixing. However, a substantial change in the pressure drop profile for velocities higher than $0.2 \mathrm{~mm} / \mathrm{s}$ was observed. The depression seen in the pressure drop profile was substantially attenuated even with the addition of $25 \mathrm{~g}$ of external particles. The trend is similar when a high proportion of external particles is added. This finding can be attributed to the elimination of non-homogeneities from the bed due to the addition of external particles. However, the pressure drop at low velocities was substantially higher when $150 \mathrm{~g}$ of external particles were added. The result is due to the bed contraction leading to a decrease in the bed void fraction, which is reflected in the high pressure drop owing to a strong dependence of the pressure drop on the bed void fraction [7]. However, as the velocity was increased further, the pressure drop decreased and became constant due to the complete fluidization. At high velocities, the low fraction mixed bed ( $25 \mathrm{~g}$ sand) did not show any improvement as the pressure drop fell as low as $600 \mathrm{~Pa}$ due to the gas bypassing caused by the formation of channels in the fluidized bed. Further addition of $25 \mathrm{~g}$ external particles nonetheless significantly improved the fluidization behavior at low and high velocities. The behavior at high velocities became comparable when the amount of external particles was increased from $75 \mathrm{~g}$ to $150 \mathrm{~g}$. At low velocity, the pressure drop for $150 \mathrm{~g}$ of sand was high due to the bed contraction phenomenon $[30,31]$. The high pressure drop at high velocity, when the bed was fully fluidized, was due to the addition of sand, leading to an increase in the effective weight of the bed. 


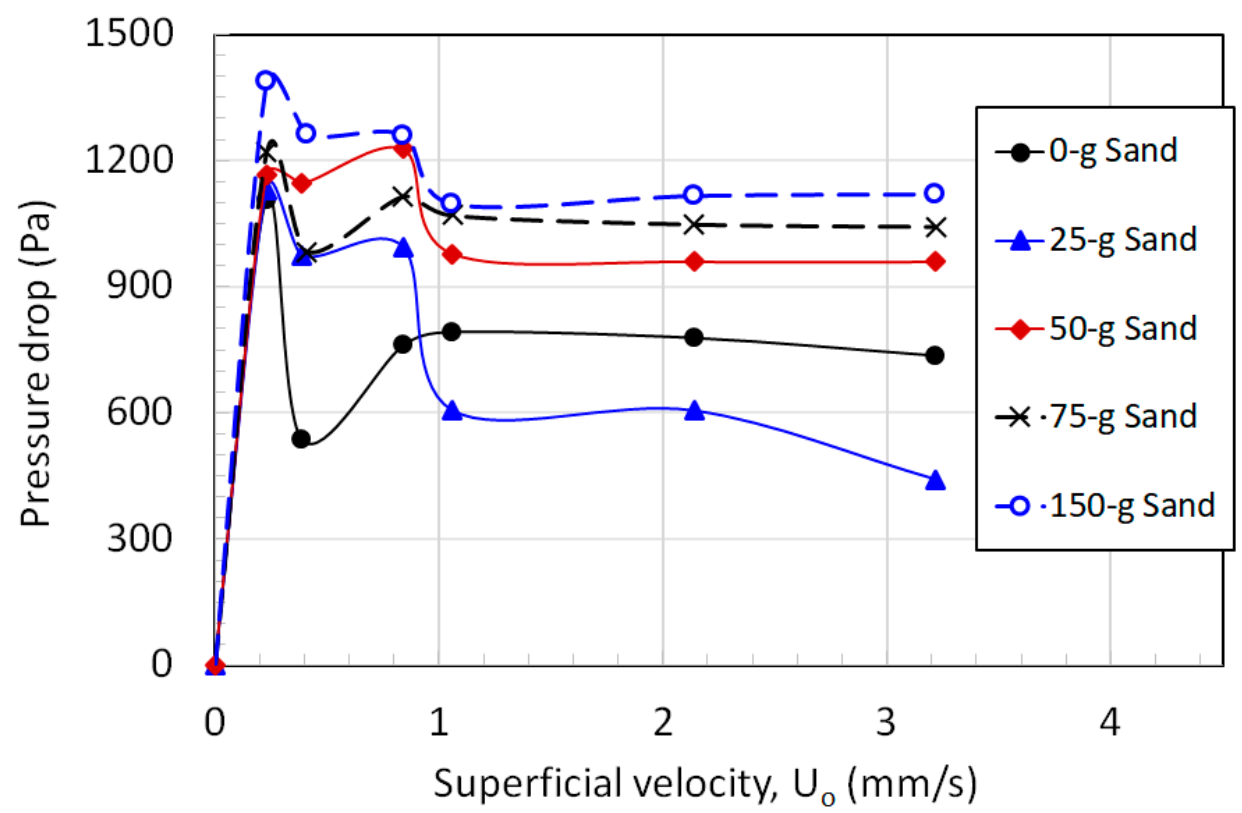

Figure 11. Effect of velocity and particle mixing on the pressure drop profile of a bed of activated carbon during fluidization at ambient conditions using nitrogen gas.

Figure 12 shows the fluidization index for the bed of activated carbon. Evidently, the FI is below unity when the bed of activated carbon contains either no external particles or very small fraction. The addition of $50 \mathrm{~g}$ of eternal particles significantly enhanced the fluidization hydrodynamics as FI is very close to unity. Further addition of $25 \mathrm{~g}$ helps to improve the fluidization behavior of the mixed bed. However, not much improvement was observed when a total of $150 \mathrm{~g}$ of external particles were added to the bed. The $\chi^{2}$ values were $0.1512,0.6788,0.0393,0.0172$, and 0.0572 for $0,25,50,75$, and $150 \mathrm{~g}$ of sand, respectively. In terms of the weight percentages, the corresponding values are $0,5,9,13$, and 23. Furthermore, the optimum fraction of external particles in our case was $13 \mathrm{wt} \%$.

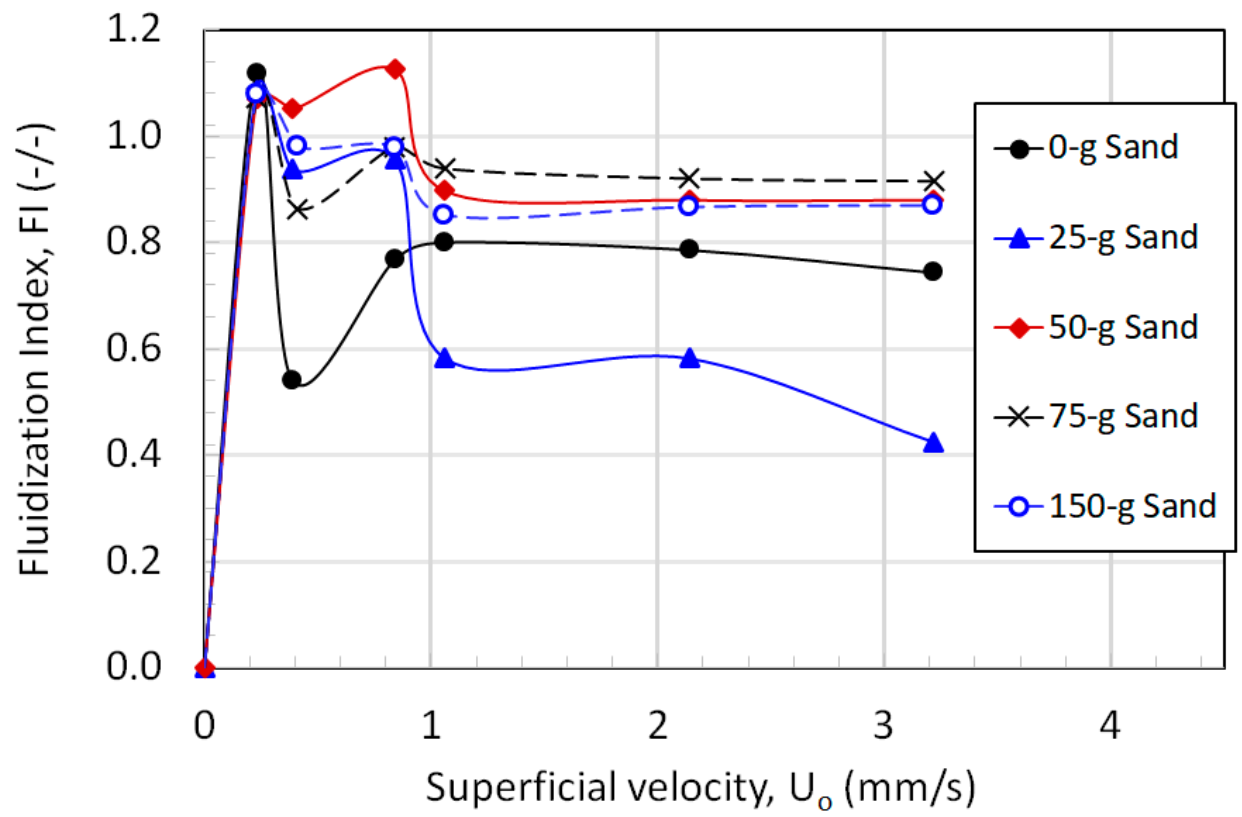

Figure 12. Effect of the addition of external particles on the fluidization hydrodynamics of the monocomponent bed and mixed bed of activated carbon and sand. 


\section{Conclusions}

In our detailed experimental investigation, the choice of two different kinds of group $C$ particles revealed a substantial difference in their fluidization behaviors. The monocomponent fluidization of the small calcium hydroxide particles led to a pressure drop that was sometimes several times higher than the effective weight of the bed. This result can be attributed to the cohesiveness of the powder, which caused a reduction in the bed void fraction, leading to an increase in the pressure drop. The initial portion of the pressure drop profile yielded a hydrodynamic diameter, which was as much as four times larger than the size obtained from the particle size analysis, mainly owing to the particle agglomeration. In fact, the SEM image of the sample also revealed the presence of the agglomeration phenomenon. The chi-squared test proves that the addition of group B particles helped to significantly enhance the fluidization behavior.

The fluidization of activated carbon was substantially different from that of the calcium hydroxide. First, the hydrodynamic diameter obtained from the pressure drop data was very close to the actual values obtained from the particle size analysis. Second, unlike the high pressure drop exhibited by the calcium hydroxide, a significant gas channeling and bypassing were observed in the bed of activated carbon, which led to a low pressure drop. Thus, the addition of group B particles improved the fluidization hydrodynamics. In these experiments, the fraction of external particle also varied. The best results were obtained for $13 \%$ external particles.

Author Contributions: Experiments were carried out by E.H.A.-G.; Conceptualization of project was contributed by A.A.; Methodology, validation, resources, project administration and original draft was contributed by M.A.; funding acquisition and writing - review and editing was contributed by A.A. and M.A.

Funding: This research was funded by the King Abdulaziz City of Science and Technology (KACST), Saudi Arabia, through the research grant number AT 35-125.

Conflicts of Interest: The authors declare no conflict of interest.

\section{References}

1. Geldart, D. Types of gas fluidization. Powder Technol. 1973, 7, 285-292. [CrossRef]

2. Ireland, E.; Pitt, K.; Smith, R. A review of pulsed flow fluidisation; the effects of intermittent gas flow on fluidised gas-solid bed behavior. Powder Technol. 2016, 292, 108-121. [CrossRef]

3. Ali, S.S.; Asif, M. Fluidization of nano-powders: Effect of flow pulsation. Powder Technol. 2012, 225, 86-92. [CrossRef]

4. Kaliyaperumal, S.; Barghi, S.; Zhu, J.; Briens, L.; Rohani, S. Effects of acoustic vibration on nano and sub-micron powders fluidization. Powder Technol. 2011, 210, 143-149. [CrossRef]

5. Valverde, J.M. Acoustic streaming in gas-fluidized beds of small particles. Soft Matter 2013, 9, 8792-8814. [CrossRef]

6. Ajbar, A.; Bakhbakhi, Y.; Ali, S.; Asif, M. Fluidization of nano-powders: Effect of sound vibration and pre-mixing with group A particles. Powder Technol. 2011, 206, 327-337. [CrossRef]

7. Ali, S.S.; Asif, M. Effect of particle mixing on the hydrodynamics of fluidized bed of nanoparticles. Powder Technol. 2017, 310, 234-240. [CrossRef]

8. Quintanilla, M.A.S.; Valverde, J.M.; Castellanos, A.; Lepek, D.; Pfeffer, R.; Dave, R.N. Nanofluidization as affected by vibration and electrostatic fields. Chem. Eng. Sci. 2008, 63, 5559-5569. [CrossRef]

9. Hristov, J. Magnetically assisted gas-solid fluidization in a tapered vessel: Part I. Magnetization-LAST mode. Particuology 2009, 7, 26-34. [CrossRef]

10. Ding, P.; Orwa, M.G.; Pacek, A.W. De-agglomeration of hydrophobic and hydrophilic silica nano-powders in a high shear mixer. Powder Technol. 2009, 195, 221-226. [CrossRef]

11. Raganati, F.; Chirone, R.; Ammendola, P. Gas-solid fluidization of cohesive powders. Chem. Eng. Res. Des. 2018, 133, 347-387. [CrossRef]

12. Shabanian, J.; Chaouki, J. Influence of interparticle forces on solids motion in a bubbling gas-solid fluidized bed. Powder Technol. 2016, 299, 98-106. [CrossRef] 
13. Shabanian, J.; Chaouki, J. Fluidization characteristics of a bubbling gas-solid fluidized bed at high temperature in the presence of interparticle forces. Chem. Eng. J. 2016, 288, 344-358. [CrossRef]

14. Xu, H.; Zhong, W.; Yuan, Z.; Yu, A.B. CFD-DEM study on cohesive particles in a spouted bed. Powder Technol. 2017, 314, 377-386. [CrossRef]

15. Ma, J.; Liu, D.; Chen, X. Bubbling behavior of cohesive particles in a two-dimensional fluidized bed with immersed tubes. Particuology 2017, 31, 152-160. [CrossRef]

16. Raganati, F.; Chirone, R.; Ammendola, P. Effect of temperature on fluidization of Geldart's group A and C powders: Role of interparticle forces. Ind. Eng. Chem. Res. 2017, 56, 12811-12821. [CrossRef]

17. Chirone, R.; Raganati, F.; Ammendola, P.; Barletta, D.; Lettieri, P.; Poletto, M. A comparison between interparticle forces estimated with direct powder shear testing and with sound assisted fluidization. Powder Technol. 2018, 323, 1-7. [CrossRef]

18. Ali, S.S.; Al-Ghurabi, E.H.; Ajbar, A.; Mohammed, Y.A.; Boumaza, M.; Asif, M. Effect of Frequency on Pulsed Fluidized Beds of Ultrafine Powders. J. Nanomater. 2016, 2016, 4592501. [CrossRef]

19. Ali, S.S.; Asif, M.; Ajbar, A. Bed collapse behavior of pulsed fluidized beds of nano-powder. Adv. Powder Technol. 2014, 25, 331-337. [CrossRef]

20. Akhavan, A.; Rahman, F.; Wang, S.; Rhodes, M. Enhanced fluidization of nanoparticles with gas phase pulsation assistance. Powder Technol. 2015, 284, 521-529. [CrossRef]

21. Bizhaem, K.H.; Tabrizi, H.B. Experimental study on hydrodynamic characteristics of gas-solid pulsed fluidized bed. Powder Technol. 2013, 237, 14-23. [CrossRef]

22. Zhu, C.; Liu, G.; Yu, Q.; Pfeffer, R.; Rave, R.N.; Nam, C.H. Sound assisted fluidization of nanoparticle agglomerates. Powder Technol. 2004, 141, 119-123. [CrossRef]

23. Ammendola, P.; Chirone, R. Aeration and mixing behaviours of nano-sized powders under sound vibration. Powder Technol. 2010, 201, 49-56. [CrossRef]

24. Si, C.; Wu, J.; Wang, Y.; Zhang, Y.; Liu, G. Effect of acoustic field on minimum fluidization velocity and drying characteristics of lignite in a fluidized bed. Fuel Process. Technol. 2015, 135, 112-118. [CrossRef]

25. Ajbar, A.; Alhumazi, K.; Asif, M. Improvement of the Fluidizability of Cohesive Powders through Mixing with Small Proportions of Group A Particles. Can. J. Chem. Eng. 2005, 83, 930-943. [CrossRef]

26. Ali, S.S.; Al-Ghurabi, E.H.; Ibrahim, A.A.; Asif, M. Effect of adding Geldart group A particles on the collapse of fluidized bed of hydrophilic nanoparticles. Powder Technol. 2018, 330, 50-57. [CrossRef]

27. Asif, M.; Kalogerakis, N.; Behie, L.A. Distributor effects in liquid fluidized beds of low density particles. AIChE J. 1991, 37, 1825-1832. [CrossRef]

28. Asif, M.; Kalogerakis, N.; Behie, L.A. Hydrodynamics of liquid fluidized beds including the distributor region. Chem. Eng. Sci. 1992, 47, 4155-4166. [CrossRef]

29. Marring, E.; Hoffmann, A.C.; Janssen, L.P.B.M. The effect of vibration on the fluidization behavior of some cohesive powders. Powder Technol. 1994, 79, 1-10. [CrossRef]

30. Asif, M. Effect of volume contraction on the incipient fluidization of binary-solid mixtures. Particuology 2011, 9, 101-106. [CrossRef]

31. Asif, M. Volume Contraction Behavior of Binary-Solid Liquid Fluidized Beds. Powder Technol. 2004, 145, 115-124. [CrossRef]

(C) 2018 by the authors. Licensee MDPI, Basel, Switzerland. This article is an open access article distributed under the terms and conditions of the Creative Commons Attribution (CC BY) license (http://creativecommons.org/licenses/by/4.0/). 